\title{
EFFECT OF YOGIC PRACTICES ON SELECTED PHYSIOLOGICAL VARIABLE AMONG POST NATAL CARE WOMEN
}

Mrs. R. Leena Devi*

*Ph. D Scholar, Centre for Yoga Studies, Annamalai University, Chidambaram, Tamilnadu, India. DOI: http://doi.org/10.47211/trr.2019.v05i02.004

Received $15^{\text {th }}$ November 2019, Accepted $5^{\text {th }}$ December 2019, Published $20^{\text {th }}$ December 2019

ABSTRACT: The purpose of the random group experimental study was to find out the effect of yogic practices on selected physiological variables among post natal care women. It was hypothesized that there would be significant differences on heart rate due to yogic practices group than the control group. To achieve the purpose of study, 30 middle aged post natal women with increases heart rate were selected from in and around gobichettipalayam city, aged between 27 o 35 were selected and assigned randomly to experimental group and control group consisting of 15 subjects each. Experimental group underwent yogic practices for 6 weeks, five days per week for maximum period of 1 hour in the morning. The control groups were kept in active rest period. The pre and post test were conducted before and after the training group for both groups. Heart rate was measured by omron digital heart rate monitor. . The obtained data were statistically analysed by using dependent $t$ test to determine the significant difference at 0.05 level of confidence. The result of the study showed that the heart rate was significantly reduced due the practices of yoga than the control group. Hence the hypothesis was accepted at 0.05 level of confidence. Thus the conclusion was that the yogic practices helped in improvement on heart rate among post natal care women than the control group.

KEY WORDS: Yogic Practices, Post Natal, Heart Rate.

\section{About Author:}

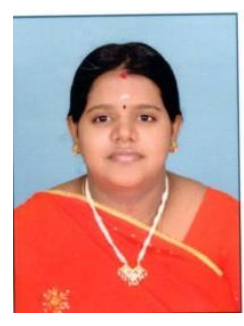

Author R. Leena Devi is Ph.D. Scholar, Centre for Yoga Studies, Annamalai University, Chidambaram, Tamilnadu, India. She has attended various national and International conferences and workshops. She has presented papers in various conferences and seminars. 


\section{INTRODUCTION}

There occurs a huge change in the lifestyle of every woman in their post natal Period ie, after delivery and they become a responsible mother, a blessed parent. Commonly post natal blues, bodily changes at all levels of all the systems. In all dimensions women experiences a very hard time to deal with. It takes over a time to attain their pre pregnancy state of health and well being but until then they really face a challenging life style each and every moment. Hence to overcome this profoundly collapsing time and to cope up with these changes yoga helps to overcome this with joy. Normally during pregnancy and before most women experience some sort of complications or alterations in their vitals eg, heart rate, blood pressure etc.

As there was rapid growth in different types of physiological and other disorders occurring in post natal mother, some dose not return back to their normal level of vital signs following post partum. Yogic practices play a major role in normalizing vital signs very soon. The current literature suggests that many disorders, including postpartum depression, other physical and physiological alteration occur high in low- and lower-middle-income countries. A systematic review of 47 studies in 18 countries reported a prevalence of $18.6 \%$.

Yoga drains away products of inflammation and toxins from joints. According to yoga joints are the storage of prana, therefore stiffness of joints and tightness of muscles are due to pranic block yoga regulates the flow of prana and gives betterment of the health also by activation and awakening of higher centers, on regular practice of yoga one can lead a healthy life overcoming all the disabilities of day to day life.

\section{PURPOSE OF STUDY}

The purpose of the study was to find out the effect of yogic practices on selected physiological variable i.e., heart rate among post natal care women

\section{HYPOTHESIS}

- It was hypothesized that there would be significant differences on heart rate among post natal care women due to yogic practices than the control group.

\section{REVEW OF RELATED LITERATURE}

\section{Effect of Yoga On Anxiety Score And Resting Heart Rate In Young Healthy Individuals Dr. Ranjita Mehrotra,}

Modern age is the age of 'anxiety and stress', which is posing a great challenge to the Health of society. Stresses of modern life precipitate various cardiovascular and other disorders by distorting basic neuroendocrine mechanism and poses risk to cardiovascular system. The objectives for the study were to assess effect of yoga practices on anxiety score (using Taylor's manifest anxiety scale) and resting heart rate. Study group included subjects who participated in yoga practices for a period of 3 months. Anxiety score was estimated with the help of Taylor's manifest anxiety scale questionnaire and resting heart rate was estimated by using electrocardiogram (ECG). At the end of three months statistically significant decrease in anxiety score and resting heart rate was observed in the study group. Whereas, there was no statistically significant difference in anxiety score and resting heart rate of control group. It is evident from the study that yoga practices of even short duration ( 3 months) can reduce anxiety status and decrease resting heart rate. 


\section{METHODOLOGY}

To fulfill the goal of the random group experimental study, Random sampling design was followed for selecting the samples. 30 middle aged women ranging from 27 to 35, with increased heart rate were selected in and around gobichettipalayam city. The subjects were assigned randomly into experimental group and control group with 15 subjects each. Experimental group was involved in yogic practices for 6 week and the control group kept in active rest. Pretest and post test were taken for both groups on selected dependent variables before and after the training Programme of six weeks

The yogic practices given were

Prayer, Pawanamuktasan ,Tadasana, Halasana, Padhahastasana, Makarasana, Matsyasana Sethubandhasana, Bujangasana, Virishikasana, Marjariasana,Shavasana, Bramari, Simple Meditation, Relaxation..

\section{DATA ANALYSS}

The data pertaining to the variables collected from the groups as pre and post test were statistically analyzed by dependent $t$ test to determine the significant differences at 0.05 level of confidence.

\section{RESULTS AND DISCUSSIONS OF HEART RATE}

The pre and post test scores of heart rate was measured and subjected to statistical treatment. The results in the effect of training of yogic practices is presented in the table1

\section{ANALYSIS OF CO-VARIANCE OF THE MEANS OF EXPERIMENTAL GROUP AND THE CONTROL GROUP IN HEART RATE (Total scores in gms.)}

\begin{tabular}{|l|l|l|l|l|l|}
\hline Group & Test & N & Mean & SD & T \\
\hline \multirow{2}{*}{ Control } & & & & & \\
\cline { 1 - 5 } & Pre test & 15 & 79.73 & 5.33 & \multirow{2}{*}{1.822} \\
\cline { 2 - 5 } & Post test & 15 & 76.60 & 3.73 & \\
\cline { 2 - 5 } & Pre test & 15 & 83.80 & 1.85 & \multirow{2}{*}{$16.97^{*}$} \\
\cline { 2 - 5 } & Post test & 15 & 66.93 & 3.36 & \\
\hline
\end{tabular}

*significant at 0.05 level of confidence, $t$ ratio at $\mathrm{df}$ at $28=2.048$

The data from the tests on heart rates of the experimental group and control groups have been statistically analyzed using dependent $t$ test and the results are presented in the table 1This shows that the pre test means of both experimental and control group were83.8 and79.73 respectively. The pre test standard deviation for the control and experimental group were5.33 and 1.85 respectively. The post test means of the control and experimental group were 76.6 and 66.93.respectively. The post test means of the control and experimental groups were 76.6 and 66.93.respectively. The post test standard deviation for control group and experimental group were3.73 and 3.36 respectively. The obtained t value 16.97 of the experimental group with respect to the heart rate was significantly higher than the required ' $t$ ' value (2.048) and it is proven that there was a significant difference in the heart rate levels of experimental group than the control group. Hence it was accepted that the yogic practices decreases the heart rate level than the control group.

The obtained mean values in pre and post test of experimental and control group were represented in bar diagram figure 1. 
FIGURE -1 BAR DIAGRAM SHOWING POST TEST AND PRE TEST VALUES OF CONTROL GROUP AND EXPERIMENTAL GROUP ON HEART RATE

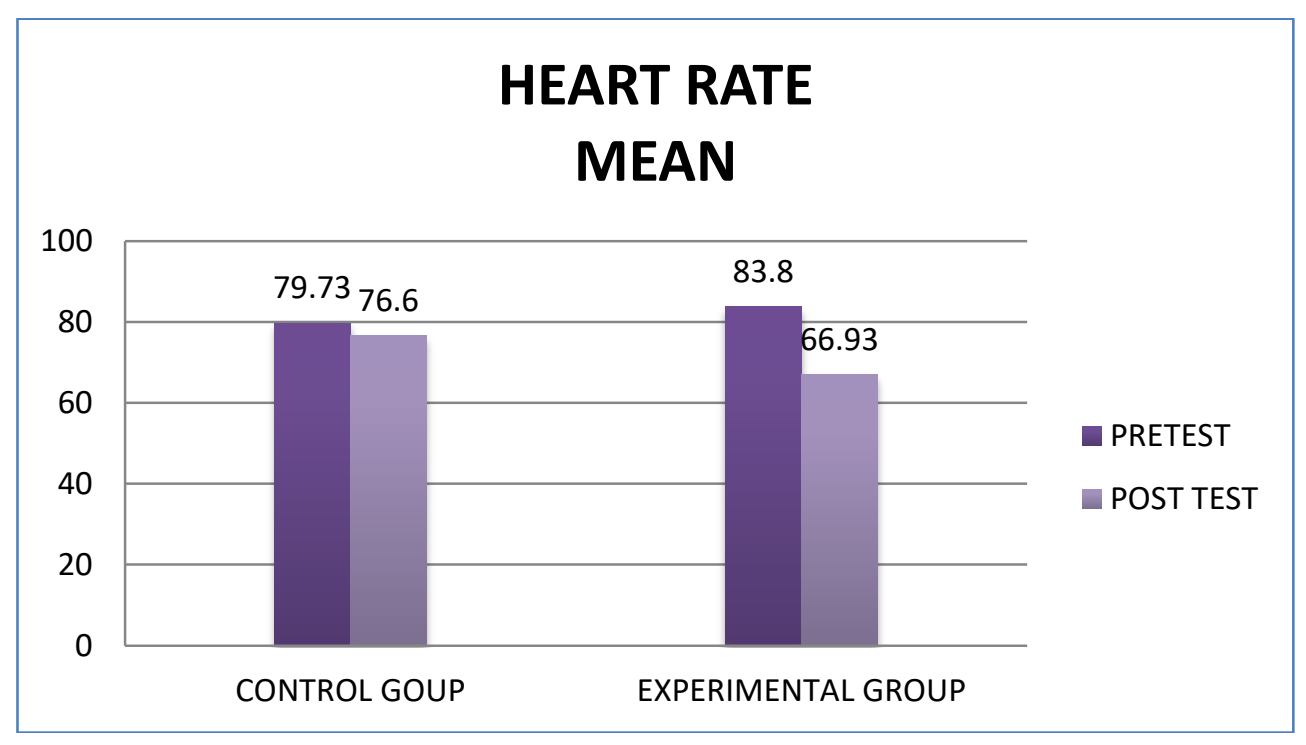

\section{DISCUSSION ON THE FINDINGS OF BLOOD HEMOGLOBIN}

The result of the study on heart rate indicates that the experimental group brought about significant decrease after the yogic training than the control group. The analysis of the data indicates that there was a significant difference on heart rate Based on the mean value; the yogic practice improves heart rate than the control group. Systematic yogic practices training control the heart rate.

\section{DISCUSSION ON FINDINGS AND HYOTHESES}

- The results of the study indicated that there was significant difference on heart rate due to the effect of yogic practices than the control group.

- Hence the hypothesis was completely accepted at 0.05 level of confidence

\section{CONCLUSION}

From the analysis and discussion of this study the following conclusions were drawn,

- Yogic practices helped to decrease heart rate among post natal care women than the control group.

\section{REFERRENCES:}

1. West Indies medical journal, vol.6.no.2.mar 2011.

2. Indian journal of applied research vol.4.july 2014.

3. Journal of Japanese society of health science and research vol.01.august 2011.

4. National journal of integrated research in medicinevol.3. (2) 2012.

5. A Principle of yoga therapy by Ananda Balayogi Bhavanani. 